\title{
PRÉ-TRATAMENTO DE SEMENTES DE ARROZ, COMO MEIO DE SUPERAR O EFEITO DA SALINIDADE NA GERMINAÇÃO E VIGOR ${ }^{1}$
}

\section{PAULO ANSELMO ANDRADE AGUIAR ${ }^{2}$}

RESUMO. O excesso de sais tem limitado a produção agrícola nas regiões áridas e semi-áridas do mundo, afetando as plantas principalmente durante a germinação e primeiros estágio de crescimento. No presente trabalho avaliou-se a germinação e vigor de sementes de arroz (Oryza sativa L.), cultivar IAC 1246, sob condições de laboratório, utilizando-se substrato salino e não salino, sendo as sementes submetidas aos seguintes pré-tratamentos: $\mathrm{T}_{1}$ (controle); $\mathrm{T}_{2}$ (imersão em água por 24 horas); $\mathrm{T}_{3}$ (imersão em solução de ácido giberélico por 24 horas); $\mathrm{T}_{4}$ (hidratação-desidrataçã̃o até o ponto crítico da emersão da radícula). Os resultados obtidos demonstram a viabilidade de utilização de pré-tratamentos como meio de superar os efeitos osmóticos e tóxicos dos sais na germinação e vigor da sementes.

Termos para indexação: pré-tratamento de sementes , Oryza sativa L., germinação, vigor e salinidade.

\section{ABSTRACT. RICE SEED PRETREATMENTS AS A TOOL TO OVERCOME SALINITY EFFECT ON GERMINATION AND VIGOR.}

In the arid and semi-arid regions of the world, the excess of salts in agricultural lands has limited crop production, being the effect greater during germination and seedling stage. In the present paper germination and vigor of rices seeds (Oryza sativa L.) cultivar IAC 1246 were evaluated under saline and nonsaline laboratory conditions. The following seeds pretreatments were used: $T_{1}$ (control); $\mathrm{T}_{2}$ (immersion in distilled water for 24 hours); $\mathrm{T}_{3}$ (immersion in gibberelic acid solution for 24 hours); $\mathrm{T}_{4}$ (hydration-dehydration up to radicle protusion). The results demonstrated the usefulness of seed pretreatments as a tool to overcome the osmotic and toxic effects of salts on germination and seed vigor.

Index terms: seed pretreatments, Oryza Sativa L., germination, vigor and salinity.

1 Contribuição do Convênio DNOCS/SUDENE/EMBRAPA. Apresentado no 1 . $^{\circ}$ Congresso Brasileiro de Sementes. Curitiba, PR., 26/11 a 02/12/79.

2 Eng. ${ }^{\circ}$ Agr. ${ }^{\circ}$, Ph. D em Tecnologia de sementes, Pesquisador do CPATSA/EMBRAPA, Rua Presidente Dutra, 160 - 56.300 - Petrolina - PE. 


\section{INTRODUÇÃO}

Nas regiōes áridas e semi-áridas do mundo o excesso de sais em áreas agrícolas tem limitado a produção das culturas, principalmente nas áreas irrigadas. A resistência ou tolerância à salinidade varia de espécie para espécie, sendo que em geral as plantas são mais sensíveis durante a germinação e primeiros estágios de crescimento (Donovan \& Day, 1969).

A presença de sais na germinação prejudica a absorção d'água pelas sementes (Uhvits, 1946), inibe a atividade de certos enzimas responsáveis pela conversão das substâncias de reserva (Zhurovskaya et al. 1972), dificulta a mobilização e síntese dessas substâncias (Prisco \& O’Leary, 1970 e Prisco \& Vieira 1976), podendo ainda inteferir no balanço hormonal da semente.

Algumas tentativas foram feitas no sentido de sobrepujar os efeitos inibitórios da salinidade na germinação e vigor através de pré-tratamentos de sementes (Lyles \& Fanning, 1964; Prisco et al. 1975 e Prisco, 1978).Os resultados obtidos são bastante promissores, todavia a vantagem parece depender principalmente do pré-tratamento utilizado.

Tendo em vista que a salinidade dos solos tem se constituido um fator limitante para a produção agrícola nas áreas irrigadas do trópico semi-árido do Brasil, planejou-se o presente trabalho para avaliar métodos de pré-tratamentos de sementes como meio de superar os efeitos deletérios da salinidade na germinação e vigor de sementes de arroz.

\section{MATERIAL E MÉTODOS}

Sementes de arroz (Oryza sativa L.), cultivar IAC 1246, produzidas pelo Serviço de Produção de Sementes Básicas, em Barbalha-Ceará , foram utilizadas no presente estudo.

As avaliações da germinação e do vigor das sementes foram efetuadas sob condições de laboratório,utilizando-se substratos salinos e não salino, sendo as sementes submetidas previamente aos seguintes tratamentos:

$\mathrm{T}_{1}$ : Testemunha (sem tratamento prévio).

$\mathrm{T}_{2}$ : Imersão em água destilada por 24 horas.

$\mathrm{T}_{3}$ : Imersão em solução de ácido giberélico (100 mg/ 1 por 24 horas).

$\mathrm{T}_{4}$ : Hidratação - desidratação das sementes (hardening).

Como substrato para a germinação foram usadas 3 folhas de papel-toalha (Gemitest, De Leo \& Cia Ltda) umedecidas em solução salina ou água destilada e envoltas com plástico para evitar perdas por evaporação. Para a avaliação do 
vigor das sementes utilizou-se a primeira contagem do teste de germinação e o crescimento da radícula e da parte aérea da plântula após 5 dias do início do teste. Os testes de germinação e de vigor foram conduzidos em germinador CASP (CASP S.A. Indústrial e Comércio, Amparo - São Paulo) regulado numa temperatura de $30^{\circ} \mathrm{C}$ sem iluminação. Para o teste de germinação e primeira contagem foram usadas 4 repetições de 50 sementes, enquanto que para o de crescimento da radícula e da parte aérea da plântula apenas 4 repetições de 25 sementes, dispostas em linha reta a $10 \mathrm{~cm}$ da borda superior do papel e colocadas no germinador em posição vertical. As plântulas normais no $5 .^{\circ}$ dia (la. contagem) e no $14 .^{\circ}$ dia (germinação) somente foram consideradas germinadas quando apresentavam sistema radicular com raízes secundárias visíveis e a parte aérea superior a $0,5 \mathrm{~cm}$ de comprimento. $O$ crescimento radicular e o da parte aérea foram obtidos dividindose o total de medições feitas em cada repetição pelo número total de sementes.

A concentração do substrato salino foi obtida misturando-se partes iguais em peso de Cloreto de Sódio $(\mathrm{NaCl})$ e Sulfato de Sódio $\left(\mathrm{Na}_{2} \mathrm{SO}_{4}\right)$ à água destilada até a obtenção de uma solução salina com $8 \mathrm{~atm}$ de potencial osmótico. $O$ cálculo do potencial osmótico foi feito através da condutividade elétrica da solução de acordo com Richards (1954).

Os pré-tratamentos de embebição das sementes $\left(\mathrm{T}_{2}, \mathrm{~T}_{3}\right.$ e $\left.\mathrm{T}_{4}\right)$, ou seja, o processo de imersão ou de hidratação foi realizado durante 24 horas, por ser o tempo determinado em testes preliminares como sendo o período crítico de emer-
são da radícula.

\section{RESULTADOS E DISCUSSÃo}

Os resultados apresentados na Tabela 1 mostram que, sob condições não salinas (água), a germinação das sementes de arroz não foi influenciada pelos prétratamentos utilizados. Entretanto, sob condições salinas observou-se que os prétratamentos subrepujaram quase que totalmente os efeitos nocivos dos sais no processo de germinação das sementes. A não diferenciação entre os pré-tratamentos utilizados em condições salinas sugerem apenas a importância físico-química da embebição prévia das sementes em superar os efeitos deletérios dos sais na germinação.

Na avaliação do efeito dos pré-tratamentos no vigor das sementes utilizouse a primeira contagem do teste de germinação (Tabela 2), crescimento radicular (Tabela 3) e da parte aérea (Tabela 4). Na Tabela 2 constata-se também que em condições não salinas os pré-tratamentos utilizados não diferiram estatisticamente do controle $\left(T_{1}\right)$; todavia , sob condições salinas, observa-se uma nítida superioridade .do pré-tratamento em que o processo de embebição é feito com solução de ácido giberélico $\left(\mathrm{T}_{3}\right)$. Isto se deve basicamente a uma ativação do crescimento 
radicular (Tabela 3) e da parte aérea das plântulas (Tabela 4). Estes parâmetros confirmam as mesmas tendências encontradas para a germinação (Tabela 1) e primeira contagem (Tabela 2).

Pode-se constatar ainda que, em termos de vigor, o tratamento de hidratação-desidratação prévia das sementes foi ineficiente em superar os efeitos nocivos dos sais, o que possivelmente se deve à desuniformidade no processo de hidratação das sementes.

Os resultados obtidos sugerem que os sais exercem efeitos nocivos nas 24 horas iniciais do processo de germinação, já que este efeito foi quase que totalmente superado pela embebição prévia das sementes. Presume-se pois que tal resultado esteja associado com a absorção d'água pelas sementes (Uhvits, 1946), inibição da atividade enzimática e conversão das substâncias de reservas (Zhukovskaya et al. 1972) além de dificuldade de mobilização e síntese dessas substâncias (Prisco \& O'Leary, 1970 e Prisco \& Vieira, 1976). Contudo nenhuma tentativa foi realizada para verificar a magnitude do efeito dos sais em çada uma dessas etapas.

TABE LA 1. Percentagem média de germinação de sementes de arroz quando pré-tratadas e semeadas em agua ou solução satina.

\begin{tabular}{lcl} 
& \multicolumn{2}{c}{$\%$ de Germinação } \\
\cline { 2 - 3 } Pré-tratamentos & Água & Solução Salina \\
\hline$T_{1}$ (Controle) & $97,0 \mathrm{a}$ & $28,0 \mathrm{~b}$ \\
$\mathrm{~T}_{2}$ (Água) & $98,5 \mathrm{a}$ & $90,5 \mathrm{a}$ \\
$\mathrm{T}_{3}$ (Sol. A.G.) & $100,0 \mathrm{a}$ & $82,0 \mathrm{a}$ \\
$\mathrm{T}_{4}$ (Hardening) & $97,5 \mathrm{a}$ & $83,0 \mathrm{a}$
\end{tabular}

Médias em cada coluna seguidas pelas mesmas letras não diferem estatisticamente pelo teste de Tukey ao nivel de $1 \%$ de probabilidade.

TABELA 2. Teste de primeira contagem de germinação de sementes de arroz quando pré-tratadas e semeadas em água ou solução salina.

\begin{tabular}{|c|c|c|}
\hline \multirow[b]{2}{*}{ Pré-tratamentos } & \multicolumn{2}{|c|}{ Primeira Contagem (\%) } \\
\hline & Água & Solução Salina \\
\hline$T_{1}$ (Controle) & $95,5 \mathrm{a}$ & $0,0 \mathrm{~b}$ \\
\hline$T_{2}$ (Água) & 98,0 a & $6,0 \mathrm{~b}$ \\
\hline$T_{3}$ (Sol. A.G.) & $100,0 \mathrm{a}$ & $210 \mathrm{a}$ \\
\hline $\mathrm{T}_{4}$ (Hardening) & 97,5 a & $1,5 \mathrm{~b}$ \\
\hline
\end{tabular}

Médias em cada coluna seguidas pela mesma letra não diferem estatisticamente pelo teste de Tukey ao nivel de $1 \%$ de probabilidade. 
TABELA3. Crescimento radicular médio de sementes de arroz quando pre-tratadas semeadas em tgua ou soluçäo salina.

\begin{tabular}{lll}
\hline & \multicolumn{2}{c}{ Crescimento radicular (cm) } \\
\cline { 2 - 3 } Pre-tratamentos & Agua & Solucão salina \\
\hline$T_{1}$ (Controle) & $12,9 \mathrm{a}$ & $2,0 \mathrm{~b}$ \\
$T_{2}$ (Agua) & $16,8 \mathrm{a}$ & $5,6 \mathrm{a}$ \\
$T_{3}$ (Sol. A.G.) & $15,8 \mathrm{a}$ & $5,9 \mathrm{a}$ \\
$T_{4}$ (Hardening) & $14,0 \mathrm{a}$ & $1,5 \mathrm{~b}$
\end{tabular}

Médias em cada coluna seguidas pela mesma letra não diferem estatisticamente pelo teste de Tukey ao nivel de $1 \%$ de probabilidade.

TABELA 4. Crescimento médio da parte aérea de sementés de arroz quando pré-tratadas e semeadas em água ou solução salina.

\begin{tabular}{lll}
\hline & \multicolumn{2}{c}{ Crescimento da parte aérea $(\mathrm{cm})$} \\
\cline { 2 - 3 } Pré-tratamentos & Água & Solução salina \\
\hline$T_{1}$ (Controle) & $3,7 \mathrm{~b}$ & $0,0 \mathrm{c}$ \\
$\mathrm{T}_{2}$ (Água) & $4,6 \mathrm{ab}$ & $0,5 \mathrm{~b}$ \\
$\mathrm{~T}_{3}$ (Sol. A.G.) & $6,5 \mathrm{a}$ & $1,0 \mathrm{a}$ \\
$\mathrm{T}_{4}$ (Hardening) & $5,5 \mathrm{ab}$ & $0,0 \mathrm{c}$
\end{tabular}

Médias em cada coluna seguidas pela mesma letra não diferem estatisticamente pelo teste de Tukey ao nível de $1 \%$ de probabilidade.

\section{CONCLUSŌES}

1. A simples embebição prévia das sementes de arroz, elimina em grande parte os efeitos nocivos dos sais na germinaç̃̃o e vigor.

2. Sob condições de substrato não salino, o efeito da embebição foi desprezível. 
3. A não diferenciação entre os pré-tratamentos utilizados sugere a importância físico-química da água em superar os efeitos deletérios dos sais na germinação.

4. A embebição das sementes com solução de ácido giberélico ativou o vigor através de um crescimento intenso da radícula e da parte aérea da plântula.

\section{REFERENCIAS}

DONOVAN, T.J. \& DAY, A.D. Some effects of high salinity on germination and emergence of barley (Hordeum vulgare L. emend Lani.) Agron. J., 61: 236-8, 1969.

LYLES, L. \& FANING, C.D. Effects of presoaking, moisture tension, and soil salinity on the emergence of grain sorghum. Agron. J., 56: 518-20, 1964.

PRISCO, J.T. \& O'LEARY, J.W. Effect of salt and water stress on protein synthesizing capacity of embryo-ax is of germinating Phaseolus vulgaris L. seeds Rev. bras. Biol., 30 (2):317-1, 1970.

PRISCO , J.T.; BARBORA, L \& FERREIRA, L.G.R. Pré-embebição como meio para sobrepujar os efeitos inibitórios da salinidade na germinação de sementes de Sorghum bicolor (L.) Moench. Cien. Agron. , $5(1-2): 19-23,1975$.

PRISCO, J.T. \& VIEIRA, G.H.F. Effects of NaCl salinity on nitrogenous compounds and proteases during germination of Vigna sinensis seeds. Phisiol Plamt., 36 : 317-320, 1976.

PRISCO, J.T.; SOUTO, G.F. \& FERREIRA, L.G.R. Overcoming salinity inhibition of sorghum seed germination by hydration-dehydration treatment. Plant and Soil, 49: 199-206,1978.

UHVITS, R. Effect of osmotic pressure on water absorption and germination of alfafa seeds. Amer. J. Bot., 33 : 278-85, 1946.

SHUKOVSHAYA, N.V.; DZHANIBEKOVA, L.S.A; GAIDAMAKINA \& L.F.\& LUTSENKO, E.F. Certain aspects of seed metabolism during germination and the effect exerted on them by salinization. Soviet Plant Physiol. , 19 (3): 517-24, 1972. 